\title{
Lactic acid level as an outcome predictor in pediatric patients with intussusception in the emergency department
}

\author{
Jeong-Yong Lee', Young-Hoon Byun ${ }^{1}$, Jun-Sung Park', Jong Seung Lee ${ }^{2}$, Jeong-Min Ryu ${ }^{2}$ and Seung Jun Choi ${ }^{*^{*}}$ (D)
}

\begin{abstract}
Background: Intussusception decreases blood flow to the bowel, and tissue hypoperfusion results in increased lactic acid levels. We aimed to determine whether lactic acid levels are associated with pediatric intussusception outcomes.

Methods: The electronic medical records of our emergency department pediatric patients diagnosed with intussusception, between January 2015 and October 2018, were reviewed. An outcome was considered poor when intussusception recurred within $48 \mathrm{~h}$ of reduction or when surgical reduction was required due to air enema failure.

Results: A total of 249 patients were included in the study, including 39 who experienced intussusception recurrence and 11 who required surgical reductions; hence, 50 patients were included in the poor outcome group. The poor and good outcome groups showed significant differences in their respective blood gas analyses for $\mathrm{pH}$ (7.39 vs. $7.41, P=.001$ ), lactic acid (1.70 vs. $1.30 \mathrm{mmol} / \mathrm{L}, P<.001)$, and bicarbonate ( $20.70 \mathrm{vs.} 21.80 \mathrm{mmol} / \mathrm{L}, P=.036)$. Multivariable logistic regression analyses showed that $\mathrm{pH}$ and lactic acid levels were the two factors significantly associated with poor outcomes. When the lactic acid level cutoff values were $\geq 1.5, \geq 2.0, \geq 2.5$, and $\geq 3.0 \mathrm{mmol} / \mathrm{L}$, the positive predictive values for poor outcomes were $30.0,34.6,50.0$, and $88.9 \%$, respectively.
\end{abstract}

Conclusion: Lactic acid levels affect outcomes in pediatric patients with intussusception; higher lactic acid levels are associated with higher positive predictive values for poor outcomes.

Keywords: Child, Emergency service hospital, Intussusception, Lactic acid, Prognosis

\section{Background}

Intussusception, an abdominal emergency, is one of the most frequent causes of bowel obstruction in the pediatric population $[1,2]$. Its treatment involves reduction, using an air or barium enema, or, in some cases, surgical reduction [3, 4]. If intussusception is not relieved, the bowel vascular supply becomes compromised, causing intestinal ischemia progression and a risk of perforation. Therefore, identifying the conditions that

\footnotetext{
* Correspondence: sjchoi@catholic.ac.kr

'Department of Pediatrics, Asan Medical Center, University of Ulsan College of Medicine, 88 Olympic-ro 43-gil, Songpa-gu, Seoul 05505, Republic of Korea

Full list of author information is available at the end of the article
}

increase the risk of a poor outcome (e.g., recurrence or difficult-to-relieve cases) is important. Previous studies have described the risk factors for recurrent intussusception, including age, presence of pathological leading points, and symptom duration [5-8]. However, the association between specific laboratory findings and outcomes has not been investigated.

Elevated lactic acid levels occur secondary to tissue hypoperfusion/hypoxia or to causes unrelated to tissue hypoxia. Hypoperfusion-driven cases include all forms of shock, post-cardiac arrest, and regional ischemia [9]. Interestingly, reversible or irreversible intestinal ischemia develops following intussusception, potentially causing

(c) The Author(s). 2020 Open Access This article is licensed under a Creative Commons Attribution 4.0 International License, which permits use, sharing, adaptation, distribution and reproduction in any medium or format, as long as you give appropriate credit to the original author(s) and the source, provide a link to the Creative Commons licence, and indicate if changes were made. The images or other third party material in this article are included in the article's Creative Commons licence, unless indicated otherwise in a credit line to the material. If material is not included in the article's Creative Commons licence and your intended use is not permitted by statutory regulation or exceeds the permitted use, you will need to obtain permission directly from the copyright holder. To view a copy of this licence, visit http://creativecommons.org/licenses/by/4.0/. The Creative Commons Public Domain Dedication waiver (http://creativecommons.org/publicdomain/zero/1.0/) applies to the data made available in this article, unless otherwise stated in a credit line to the data. 
elevated lactic acid levels. In this study, we evaluated the association between lactic acid levels at the time of intussusception diagnosis and outcomes.

\section{Methods}

This retrospective study analyzed data retrieved from the electronic medical records of pediatric patients diagnosed with intussusception, between January 2015 and October 2018 in our emergency department (ED). Patients diagnosed with the ileo-colic type of intussusception, which is primarily treated using non-surgical reduction, were included. An outcome was defined as poor when (1) nonsurgical reduction failed and the patient required surgery, (2) intussusception recurred during the post-procedural observation period, in the ED, following nonsurgical reduction, or (3) the patient revisited the ED due to recurrence within $48 \mathrm{~h}$ of nonsurgical reduction. Patients were excluded if leading points that increase the risk of recurrence, like polyps or a diverticulum, were identified during their abdominal ultrasound examination; the patient was discharged against the physician's advice; or when the initial blood gas analysis results were missing.

The collected patient data included demographic data, symptoms at initial presentation, time between symptom onset and hospital visit, time between symptom onset and nonsurgical reduction, number of nonsurgical reduction attempts, whether or not surgical reduction was performed, intussusception recurrence, and venous blood gas analysis (VBGA) results ( $\mathrm{pH}$, lactic acid, and bicarbonate levels).

Following our institutional protocol, when intussusception was clinically suspected, the pediatric emergency physician performed a point-of-care ultrasound (POCUS) examination. If the POCUS results led to an intussusception diagnosis, rapid intravenous hydration was performed and a radiologist was simultaneously consulted to perform a fluoroscopy-guided air enema, as soon as possible. The degree of acid-base imbalance and lactic acid levels were evaluated prior to intravenous hydration, using a blood gas analyzer. If the air enema was successful, the patient remained in the ED without orally consuming anything for $6 \mathrm{~h}$. Thereafter, possible recurrence was ruled out using either plain radiography or POCUS. In the absence of recurrence, the patient was started on a liquid diet and was discharged, after confirming the absence of emesis and abdominal pain. If the air enema failed to relieve the intussusception, or when there was recurrence during the post-procedural observation period, another enema was attempted or pediatric surgeons were consulted regarding surgical intervention.

All statistical analyses were performed using IBM SPSS Statistics for Windows, version 21.0 (IBM Corp., Armonk, New York). The included patients were divided into the poor and good outcome groups and compared for differences in demographic data and clinical parameters using Wilcoxon rank-sum tests, chi-square tests, or Fisher's exact tests, as appropriate. Risk factor analysis for the prediction of poor outcomes was conducted using multivariable logistic regression model. Reliability values (sensitivity and specificity) and predictive values (positive predictive value and negative predictive value) for poor outcomes were analyzed using different lactic acid cutoff levels. For all analyses, $P$ values $<.05$ were considered statistically significant.

\section{Results}

A total of 296 patients with ileo-colic intussusception visited the ED during the study period. Of these, 249 patients were included in the analysis, after excluding patients with incomplete data (no VBGA results or missing $\mathrm{pH}$, lactic acid, or bicarbonate measurements, $n=39$ ), leading points $(n=5)$, or who had been transferred to other hospitals $(\mathrm{n}=3)$. The median age of the included patients was 1.8 years, and $63.9 \%$ were male. The clinical and demographic characteristics of patients are summarized in Table 1. Fifty patients were included in the poor outcome group, including 11 who underwent surgical reductions due to air enema failures, 20 who experienced recurrence during the post-procedural observation period, and 19 who otherwise suffered recurrence.

The clinical parameters (age, sex, symptoms at the initial visit, time between symptom onset and hospital visit, and time between symptom onset and nonsurgical reduction) were similar between the good and poor outcome groups. However, $\mathrm{pH}$, lactic acid, and bicarbonate levels were significantly different between the two groups (Table 2). Among these three possible risk factors, the multivariable logistic regression analysis indicated that only $\mathrm{pH}$ and lactic acid levels were significantly different between the two groups (Table 3).

Table 1 Clinical and demographic characteristics of patients $(n=249)$

\begin{tabular}{ll}
\hline Characteristic & Value \\
\hline Age, years & $1.8[1.1,2.7]$ \\
Male, n (\%) & $159(63.9)$ \\
Symptom ${ }^{a}$ & \\
$\quad$ Abdominal pain/irritability, n (\%) & $207(83.1)$ \\
$\quad$ Vomiting, n (\%) & $96(38.6)$ \\
$\quad$ Blood-tinged stool, n (\%) & $41(16.5)$ \\
Time between symptom onset and hospital visit (hours) & $7.5[3.0,24.0]$ \\
Time between symptom onset and air reduction (hours) & $9.0[5.0,25.0]$ \\
Surgery, n (\%) & $11(4.4)$ \\
\hline
\end{tabular}

Results are presented as medians [interquartile range] and numbers (\%) ${ }^{a}$ Multiple symptoms were listed if more than one was described by the patient or parents 
Table 2 Clinical parameters compared according to outcome

\begin{tabular}{|c|c|c|c|}
\hline & Poor outcome $(n=50)$ & Good outcome $(n=199)$ & $P$ \\
\hline Age, years & $1.92[1.17,3.10]$ & $1.83[1.08,2.67]$ & .418 \\
\hline Male, n (\%) & $35(70.0)$ & $124(62.3)$ & .329 \\
\hline \multicolumn{4}{|l|}{ Symptom ${ }^{a}$} \\
\hline Abdominal pain/irritability, n (\%) & $43(86.0)$ & $164(82.4)$ & .762 \\
\hline Vomiting, n (\%) & $21(42.0)$ & $75(37.7)$ & .627 \\
\hline Blood-tinged stool, n (\%) & $7(14.0)$ & $34(17.1)$ & .675 \\
\hline Time between symptom onset and hospital visit (hours) & $8.50[2.00,38.00]$ & $7.00[3.00,24.00]$ & .459 \\
\hline Time between symptom onset and air reduction (hours) & $10.50[4.00,39.00]$ & $9.00[5.00,25.00]$ & .425 \\
\hline \multicolumn{4}{|l|}{ Venous blood gas analysis } \\
\hline $\mathrm{pH}$ & $7.39[7.36,7.43]$ & $7.41[7.38,7.45]$ & .001 \\
\hline Lactic acid (mmol/L) & $1.70[1.30,2.33]$ & $1.30[1.08,1.70]$ & $<.001$ \\
\hline Bicarbonate (mmol/L) & $20.70[19.25,22.65]$ & $21.80[20.00,23.50]$ & .036 \\
\hline
\end{tabular}

Results are presented as medians [interquartile range] and numbers (\%)

${ }^{a}$ Multiple symptoms were listed if more than one was described by the patient or parents

When the predictive values for poor outcomes were evaluated using different lactic acid cutoff levels, the cutoff values of $1.5 \mathrm{mmol} / \mathrm{L}, 2.0 \mathrm{mmol} / \mathrm{L}, 2.5 \mathrm{mmol} / \mathrm{L}$, and $3.0 \mathrm{mmol} / \mathrm{L}$ yielded positive predictive values of 30.0 , $34.6,50.0$, and $88.9 \%$, respectively; the respective negative predictive values were $87.8,83.8,82.5$, and $82.5 \%$ (Table 4).

\section{Discussion}

From our study results, we found out that lower $\mathrm{pH}$ values and higher lactic acid levels were associated with greater likelihoods of intussusception recurrence. Notably, although the difference in the numerical $\mathrm{pH}$ values between the groups was statistically significant, the values for both groups were within the normal range. Thus, the lactic acid level is probably the only clinically meaningful parameter associated with poor outcomes in this setting. Using different lactic acid cutoff levels $(\geq 1.5$, $\geq 2.0, \geq 2.5$, and $\geq 3.0 \mathrm{mmol} / \mathrm{L}$ ), all of the determined negative predictive values were high but the positive predictive values increased as the cutoff values increased. In particular, the positive predictive value for a poor outcome increased from 50 to $88.9 \%$ when the cutoff value was increased from $\geq 2.5 \mathrm{mmol} / \mathrm{L}$ to $\geq 3.0 \mathrm{mmol} / \mathrm{L}$.
In previous studies, patient lactic acid levels were reported to be poor parameters for diagnosing intussusception [10]. Hence, the diagnostic method of choice is ultrasonography [11]. However, a recent study showed that POCUS, performed by emergency physicians, had a similar diagnostic accuracy as radiologist-performed ultrasound [12]. POCUS is widely used in many institutions, including ours, because it can be promptly performed in the ED.

Based on our study results, lactic acid levels were found to be potential predictors of poor outcomes in pediatric intussusception patients. Although there is no clear definition for an "elevated" lactic acid level, most previous studies report levels of 2.0 or $2.5 \mathrm{mmol} / \mathrm{L}$ to indicate elevation [13]. In our study, when a $2.5-\mathrm{mmol} / \mathrm{L}$ cutoff was used, $50 \%$ of the patients presented poor outcomes; when a $3.0-\mathrm{mmol} / \mathrm{L}$ cutoff was used, the positive predictive value increased to $88.9 \%$.

In patients presenting with abdominal pain associated with suspicious mesenteric ischemia, lactic acid level measurements can help guide further diagnostic workups [14]. According to Lange et al., elevated lactic acid levels showed a $96 \%$ sensitivity and $38 \%$ specificity for indicating mesenteric ischemia [15]. Furthermore,

Table 3 Multivariable logistic regression analysis for the prediction of poor outcomes

\begin{tabular}{lll}
\hline Variables & aOR (95\% Cl) & $P$ \\
\hline Age & $1.026(1.003-1.049)$ & .024 \\
Time between symptom onset and hospital visit (hours) & $0.868(0.556-1.354)$ & .531 \\
Time between symptom onset and air reduction (hours) & $1.163(0.745-1.814)$ & .507 \\
$\mathrm{pH}$ & $0.000(0.000-0.033)$ & .003 \\
Lactic acid (mmol/L) & $3.066(1.694-5.551)$ & $<.001$ \\
Bicarbonate $(\mathrm{mmol} / \mathrm{L})$ & $0.889(0.759-1.042)$ & .148 \\
\hline
\end{tabular}

aOR Adjusted odds ratio, $\mathrm{Cl}$ Confidence interval 
Table 4 Predictive values associated with lactic acid levels

\begin{tabular}{lllllll}
\hline Lactic acid level $(\mathrm{mmol} / \mathrm{L}, \mathrm{n})$ & $\begin{array}{l}\text { Sensitivity } \\
(\%, \mathrm{n})\end{array}$ & $\begin{array}{l}\text { Specificity } \\
(\%, \mathrm{n})\end{array}$ & $\begin{array}{l}\text { PPV } \\
(\%, \mathrm{n})\end{array}$ & $\begin{array}{l}\text { NPV } \\
(\%, \mathrm{n})\end{array}$ & $\begin{array}{l}\text { OR } \\
(95 \% \mathrm{Cl})\end{array}$ \\
\hline$\geq 1.5(110 / 249)$ & $66.0(33 / 50)$ & $61.3(122 / 199)$ & $30.0(33 / 110)$ & $87.8(122 / 139)$ & $3.076(1.604-5.897)$ & .001 \\
$\geq 2.0(52 / 249)$ & $36.0(18 / 50)$ & $82.9(165 / 199)$ & $34.6(18 / 52)$ & $83.8(165 / 197)$ & $2.730(1.376-5.417)$ \\
$\geq 2.5(20 / 249)$ & $20.0(10 / 50)$ & $95.0(189 / 199)$ & $50.0(10 / 20)$ & $82.5(189 / 229)$ & $4.725(1.845-12.103)$ \\
$\geq 3.0(9 / 249)$ & $16.0(8 / 50)$ & $99.5(198 / 199)$ & $88.9(8 / 9)$ & $82.5(198 / 240)$ & $37.714(4.594-309.634)$ & .006 \\
\hline
\end{tabular}

PPV Positive predictive value, NPV Negative predictive value, OR Odds ratio, Cl Confidence interval

serum lactic acid levels $>2 \mathrm{mmol} / \mathrm{L}$ may be associated with irreversible intestinal ischemia [16]. In our study, none of the 11 patients who underwent surgical reduction required resection due to bowel ischemia. XianMing et al. concluded that the median time between symptom onset and operative treatment for intussusception was longer in patients who lost intestinal viability $(42 \mathrm{~h})$ than for those who did not $(19 \mathrm{~h})$ [17]. In our study, the median time between symptom onset and the procedure was $9 \mathrm{~h}$, which was shorter than that reported by Xian-Ming et al., suggesting that intestinal viability had been preserved.

This study has some limitations. The retrospective nature of the study is the first limitation. Secondly, due to our institutional protocol, only VBGA were performed for most of the patients. Thus, we were unable to analyze the presence of leukocytosis or hemoconcentration, which can be observed in patients with acute mesentery ischemia. Nevertheless, elevated lactic acid levels are early signs of tissue hypoxia and can be used as markers for mesenteric ischemia that are more specific than $\mathrm{C}$-reactive protein levels or leukocyte counts [18, 19]. Future research should include a large, prospectively registered population with additional laboratory findings available for analysis. Furthermore, an evaluation of the association between serial lactic acid levels and outcomes is warranted.

To the best of our knowledge, this is the first study to elucidate an association between intussusception outcomes and laboratory data. Although only a few variables were analyzed, we successfully elucidated an association between the increased risk of poor outcome and increased lactic acid levels; theoretically, lactic acid is a marker of tissue hypoperfusion.

\section{Conclusion}

Elevated lactic acid levels are associated with poor outcomes in pediatric patients with intussusception. In particular, lactic acid levels $\geq 2.5 \mathrm{mmol} / \mathrm{L}$ imply a greater risk for failed nonsurgical reduction or intussusception recurrence, warranting preparedness for alternative treatment strategies.

\section{Abbreviations}

ED: Emergency department; POCUS: Point-of-care ultrasound; VBGA: Venous blood gas analysis

\section{Acknowledgements}

Not applicable.

\section{Authors' contributions}

JYL and SJC conceived the study and drafted the manuscript; YHB, JSP, JSL and JMR participated in the collection of data and contributed to the analysis. All of the authors revised the manuscript and approved final version of the mannuscript.

\section{Funding}

Not applicable.

\section{Availability of data and materials}

The datasets used and analyzed during the current study are not publicly available due to their containing information that could compromise the privacy of study participants, but are available from the corresponding author on reasonable request.

\section{Ethics approval and consent to participate}

The institutional review board of Asan Medical Center approved this study and waived the requirement for informed consent (study number: 2020-0021).

\section{Consent for publication}

Not applicable.

\section{Competing interests}

The authors declare that they have no competing interests.

\section{Author details}

${ }^{1}$ Department of Pediatrics, Asan Medical Center, University of Ulsan College of Medicine, 88 Olympic-ro 43-gil, Songpa-gu, Seoul 05505, Republic of Korea. ${ }^{2}$ Department of Emergency Medicine, Asan Medical Center, University of Ulsan College of Medicine, 88 Olympic-ro 43-gil, Songpa-gu, Seoul 05505, Republic of Korea.

Received: 20 December 2019 Accepted: 20 April 2020

Published online: 24 April 2020

\section{References}

1. World Health Organization: Vaccines and Biologicals: Acute intussusception in infants and children. Incidence, clinical presentation and management: a global perspective. https:/apps.who.int/iris/bitstream/handle/10665/67720/ WHO_V-B_02.19_eng.pdf? sequence=1\&isAllowed=y (2002). Accessed 1 Nov 2019.

2. Huppertz HI, Soriano-Gabarro M, Grimprel E, Franco E, Mezner Z, Desselberger $\mathrm{U}$, et al. Intussusception among young children in Europe. Pediatr Infect Dis J. 2006:25:S22-9.

3. Pepper VK, Stanfill AB, Pearl RH. Diagnosis and management of pediatric appendicitis, intussusception, and Meckel diverticulum. Surg Clin North Am. 2012:92:505-26 vii.

4. Samad L, Marven S, El Bashir H, Sutcliffe AG, Cameron JC, Lynn R, et al. Prospective surveillance study of the management of intussusception in UK and Irish infants. Br J Surg. 2012;99:411-5. 
5. Shen G, Zhang C, Li J, Zhang J, Liu Y, Guan Z, et al. Risk factors for shortterm recurrent intussusception and reduction failure after ultrasoundguided saline enema. Pediatr Surg Int. 2018;34:1225-31.

6. Guo WL, Hu ZC, Tan YL, Sheng M, Wang J. Risk factors for recurrent intussusception in children: a retrospective cohort study. BMJ Open. 2017;7: e018604.

7. Xie X, Wu Y, Wang Q, Zhao Y, Xiang B. Risk factors for recurrence of intussusception in pediatric patients: a retrospective study. J Pediatr Surg. 2018;53:2307-11.

8. Kim JH, Lee JS, Ryu JM, Lim KS, Kim WY. Risk factors for recurrent intussusception after fluoroscopy-guided air Enema. Pediatr Emerg Care. 2018;34:484-7.

9. Andersen LW, Mackenhauer J, Roberts JC, Berg KM, Cocchi MN, Donnino MW. Etiology and therapeutic approach to elevated lactate levels. Mayo Clin Proc. 2013:88:1127-40.

10. Tamas V, Ishimine P. Comparison of lactic acid levels in children with suspected and confirmed intussusception. J Emerg Med. 2017:53:815-8.

11. Ko HS, Schenk JP, Troger J, Rohrschneider WK. Current radiological management of intussusception in children. Eur Radiol. 2007;17:2411-21.

12. Tsou PY, Wang YH, Ma YK, Deanehan JK, Gillon J, Chou EH, et al. Accuracy of point-of-care ultrasound and radiology-performed ultrasound for intussusception: a systematic review and meta-analysis. Am J Emerg Med. 2019:37:1760-9.

13. Kruse O, Grunnet N, Barfod C. Blood lactate as a predictor for in-hospital mortality in patients admitted acutely to hospital: a systematic review. Scand J Trauma Resusc Emerg Med. 2011:19:74.

14. Liao XP, She YX, Shi CR, Li M. Changes in body fluid markers in intestinal ischemia. J Pediatr Surg. 1995;30:1412-5.

15. Lange $H$, Toivola A. Warning signals in acute abdominal disorders. Lactate is the best marker of mesenteric ischemia. Lakartidningen. 1997;94:1893-6.

16. Nuzzo A, Maggiori L, Ronot M, Becq A, Plessier A, Gault N, et al. Predictive factors of intestinal necrosis in acute mesenteric ischemia: prospective study from an intestinal stroke center. Am J Gastroenterol. 2017:112:597-605.

17. Yao XM, Chen ZL, Shen DL, Zhou QS, Huang SS, Cai ZR, et al. Risk factors for pediatric intussusception complicated by loss of intestine viability in China from June 2009 to may 2014: a retrospective study. Pediatr Surg Int. 2015; 31:163-6.

18. Block T, Nilsson TK, Bjorck M, Acosta S. Diagnostic accuracy of plasma biomarkers for intestinal ischaemia. Scand J Clin Lab Invest. 2008;68:242-8.

19. Meyer ZC, Schreinemakers JM, van der Laan $L$. The value of C-reactive protein and lactate in the acute abdomen in the emergency department. World J Emerg Surg. 2012;7:22

\section{Publisher's Note}

Springer Nature remains neutral with regard to jurisdictional claims in published maps and institutional affiliations.

Ready to submit your research? Choose BMC and benefit from:

- fast, convenient online submission

- thorough peer review by experienced researchers in your field

- rapid publication on acceptance

- support for research data, including large and complex data types

- gold Open Access which fosters wider collaboration and increased citations

- maximum visibility for your research: over $100 \mathrm{M}$ website views per year

At $\mathrm{BMC}$, research is always in progress.

Learn more biomedcentral.com/submissions 